\title{
A nova biblioteca básica brasileira: ideia pioneira, nativa, e progressista
}

\author{
Bruno Adriano Rodrigues da Silva - Universidade Federal de Lavras (UFLA) \\ Regis Argüelles da Costa - Universidade Federal Fluminense (UFF)
}

Não havendo estudado em universidades estrangeiras, não fui colonizado culturalmente, nem me embasbaquei. Não tendo sido socializado debaixo do velho regime catedrático - mesmo porque minha carreira científica foi mais de pesquisador do que de professor - não conheci servidões acadêmicas e em consequência, podia atuar como livre atirador no campo universitário (Darcy Ribeiro, 1978, p. 18).

O desafio de problematizar uma iniciativa de tamanho vulto como a Nova Biblioteca Básica Brasileira (Nova BBB), ação realizada pela Fundação Darcy Ribeiro (Fundar) em 2012, está naquilo que ela guarda de peculiar, desde a sua idealização por Darcy Ribeiro, ainda em 1962, no contexto de criação da Universidade de Brasília: ela permanece uma ideia inovadora, muito à frente do seu tempo. Corremos o risco, dessa forma, de não acompanhar essa dinâmica, caso nosso ato de problematizar incorra no equívoco de cristalizar entendimentos sobre a Nova BBB. Esse não é o nosso objetivo.

Essa negação inicial é um delimitador desse pequeno ensaio/apresentação sobre a Nova $\mathrm{BBB}$, até por que, diante de tal desafio, dizer aquilo que não faremos nos parece ser um ato de prudência, em função da clareza daquilo que queremos fazer. Nosso objetivo, doravante, é conferir à Nova BBB aquilo que ela possui de original e que, em nossa opinião, nem a dinâmica da história será capaz de colocar em seus porões. Ela é uma ideia, traduzida em ação, pioneira, nativa e progressista. Por que acreditamos nisso?

Darcy Ribeiro, como a epígrafe elucida, foi um intelectual de ação, um "livre atirador" e como tal, muitas vezes, sofreu ações reversas por se colocar frontalmente nos campos de batalha. Militou pelos índios como antropólogo, militou pelos mais pobres como sociólogo, por uma literatura originalmente brasileira como ensaísta, e militou pelo direito universal à educação como educador e ocupante de cargos políticos na estrutura do Estado brasileiro. De acordo com Bomeny (2001) foi essa inquietante e dinâmica atuação na vida pública brasileira, preenchida por características pessoais para lá de peculiares, que conferiram a Darcy Ribeiro a ideia de um intelectual "indisciplinado".

Como a Nova BBB parte da idealização de um "indisciplinado", o caminho a ser percorrido nesse ensaio/apresentação como forma de problematizá-la está descrito na própria indisciplina de Revista Interinstitucional Artes de Educar. Rio de Janeiro, V. 3 N.2 - pag 172- 177 (jul/out2017): "Número Esperial Darcy Ribeiro" DOI: 10.12957/riae.2017.31720 
Darcy Ribeiro, uma vez que ele era e, por consequência as suas ideias, um pioneiro ou nas palavras de Bomeny (op.cit.) o "último expoente da escola nova", um defensor de uma teoria que explicasse a originalidade brasileira, àquilo que era nativo às dinâmicas das relações sociais (CASTRO, 2001) do povo brasileiro, e progressista, uma vez que ele acreditava nas transformações que a política partidária, notadamente a educacional, poderia causar na estrutura social brasileira, demarcada por ele como extremamente injusta por ser desigual economicamente.

Dessa forma, por que pioneiro? Por que um intelectual associado à escola nova, movimento educacional que defendia um sistema nacional de educação com democracia, descentralização, motivações individuais e orientações filosóficas, pautado em uma organização integradora que combinasse filosofia e ciência? Porque Darcy Ribeiro conviveu e associou o seu senso militante à sensibilidade de Anísio Teixeira, integrante desse movimento. Essa declarada associação aos ideais de Anísio foi usada por Darcy para pensar a educação sob a ótica das ciências sociais, e desenvolver projetos e programas que o primeiro mantinha em pauta: "Percorrendo as biografias, é possível dizer que Darcy cumpriu uma agenda de atuação pública que lhe foi desenhada com régua e compasso por Anísio Teixeira" (BOMENY, idem, p. 219).

Ao pensar o plano editorial da BBB ainda em 1962, nesse sentido, e vinculá-lo a um projeto educacional em curso, tal qual a Universidade de Brasília (instituição da qual Darcy era Reitor) que cumpriria uma função social naquilo que dizia respeito à educação, Darcy empreendeu o que se esperava das instituições educacionais na construção de uma sociedade democrática, capaz de interferir no plano da desigualdade de acesso às oportunidades educacionais. A princípio, em 1963, as primeiras 10 obras previstas de uma coleção de 100 títulos foram viabilizadas (15.000 livros) por iniciativa do próprio Darcy Ribeiro, não mais Reitor da UnB, mas exercendo outro cargo público, o de Ministro da Educação, durante o governo de João Goulart, interrompido em 1964 pela intervenção civil-militar que, inclusive, foi a responsável direta pela interrupção do plano editorial previsto para a BBB em 1962.

Tratava-se de um projeto de características ambiciosas, que dialogava profundamente com formulações de Darcy sobre a história e a cultura brasileira. Para ele o Brasil, apesar de ter constituído tanto a uniformidade cultural quanto a unidade nacional em seu processo civilizatório, foi também marcado por gritantes conflitos e opressões de classe, que insistem em se manter e nos dividir.

O espantoso é que os brasileiros, orgulhosos de sua tão proclamada, como falsa, "democracia racial", raramente percebem os profundos abismos que aqui separam os estratos sociais. $\mathrm{O}$ mais grave é que esse abismo não 
conduz a conflitos tendentes a transpô-lo, porque se cristalizam num modus vivendi que parta os ricos dos pobres, como se fossem castas e guetos. Os privilegiados simplesmente se isolam numa barreira de indiferença para com as sinas dos pobres, cuja miséria repugnante procuram ignorar ou ocultar numa espécie de miopia social, que perpetua a alternidade. (RIBEIRO, 1995, p. 24)

Darcy acreditava que a superação deste estado de coisas, questão à qual devotou suas melhores energias, passava por um estágio de reconhecimento amplo das contradições que atravessaram a formação histórica do Brasil ou, nas palavras do próprio, a "compreensão da história vivida" (op.cit., p. 26). O povo brasileiro deveria desenvolver a autoconsciência dos porquês "da situação de dependência e opressão em que vive e peleja" (Idem., p. 25) expressos, por exemplo, pelas chacinas constantes dos povos indígenas e negros perpetradas ao longo de nossa história. Tal forma autoritária de condução do país pelas classes dominantes foi também marcada por "revoluções preventivas" (Ibid), através das quais almejam sufocar quaisquer manifestações de autodeterminação da vontade popular e de integração democrática e livre dos povos da América Latina.

O momento de autoconhecimento, apesar de fundamental, não bastava a Darcy. Era preciso ir além. A superação dos antagonismos entre o "povo-massa" e as classes dominantes demandava, ao mesmo tempo, um esforço no sentido da sistematização e ampliação do horizonte cultural daquele povo-massa. O amálgama concreto entre a cultura popular e a cultura erudita é um ideal caro às concepções de escola e de sociedade democrática partilhadas por Darcy Ribeiro: trata-se da construção da diversidade na unidade, de uma sociedade que saiba respeitar e valorizar sua multiplicidade enquanto diferentes manifestações de brasilidade, trabalhando ao mesmo tempo nos registros local e universal. Tal operação poderia, enfim, liberar as energias necessárias para a redefinição de nosso processo civilizatório rumo às suas potencialidades emancipatórias, como ele acreditava.

A BBB buscou se inserir estrategicamente nas problemáticas de superação das clivagens histórico-culturais apontadas acima. Tratava-se de editar e disponibilizar, de acordo com a concepção de Darcy, os 100 livros que todo brasileiro deveria ler. Ora, ao olharmos para a amplitude dos autores desta coleção, tais como Antonil, Padre Antonio Vieira, Machado de Assis, Tomas António Gonzaga, Lima Barreto, Manuel Bomfim, Américo Vespúcio, João do Rio, dentre outros, podemos ver o cuidado em abarcar tanto as clássicas interpretações históricas da colonização europeia da América quanto as mais importantes manifestações literárias brasileiras editadas entre o século XVI e o início do século XX. Vista em sua totalidade, a BBB se propõe a 
ser nada menos que um programa cultural de âmbito nacional, construído a partir desses vetores de democratização da cultura: conhecimento da história e da sociedade brasileira e latinoamericana; divulgação, ampliação e integração das culturas populares e erudita.

No plano editorial da Nova BBB, projeto pensado pela Fundar, 50 anos depois, novamente a responsabilidade institucional em direção à democratização da cultura, pioneira, tão cara a Darcy, está presente. Uma responsabilidade ampliada é verdade, com maior vulto e interferência, na medida em que além da disponibilidade digital ${ }^{1}$, tais obras podem ser solicitadas por escolas, instituições de ensino e pesquisa e bibliotecas públicas, algo que confere maior capilaridade à ação. Ao todo, nesse primeiro momento, foram disponibilizadas 50 obras de um plano editorial que prevê uma coleção de 150 que versam e problematizam o Brasil e a suas questões. Vale destacar ainda que a continuidade ao empreendimento inicial de Darcy Ribeiro ainda nos anos 1960 está garantida pela manutenção dos temas que ele mesmo definiu como norteadores da BBB, a saber: "O Brasil e os brasileiros; Os cronistas da edificação; Cultura popular e cultura erudita; Estudos brasileiros e Criação literária"2.

Retomando o percurso indisciplinado de Darcy Ribeiro, por que consideramos a Nova BBB como uma ação nativa à realidade brasileira? Porque o substrato que alimenta esse novo empreendimento é o mesmo que alimentou a ideia inicial de Darcy à frente da UnB, o povo brasileiro. Em suas próprias palavras:

(...) Somos um povo em ser impedido de sê-lo. Um povo mestiço na carne e no espírito, já que aqui a mestiçagem jamais foi um crime ou pecado. Nela fomos feitos e ainda continuamos nos fazendo. Essa massa de nativos oriundos da mestiçagem viveu por séculos sem consciência de si, afundada na ninguendade. Assim foi até se definir como uma nova identidade étnico-racial, a de brasileiros. Um povo até hoje, em ser, na dura busca de seu destino, olhando-os, ouvindo-os, é fácil perceber que são, de fato, uma nova romanidade, uma romanidade tardia, mas melhor, porque lavada em sangue índio e sangue negro (1995, p. 447).

De acordo com Castro (2001) aquilo que é "nativo", conforme o olhar de uma vertente da antropologia, é uma forma de determinar os problemas e questões que são oriundos de uma formação cultural específica e não, simplesmente, encontrá-los sob o olhar daquilo que é externo a eles, advindo de outras culturas. Darcy Ribeiro ao propor a BBB e a Fundar ao propor a sua ampliação estabelecem a possibilidade, em função da oportunidade educacional criada, de determinarmos os nossos "problemas" e as nossas próprias "questões" porque ela difunde, por 
meio das obras selecionadas, aspectos e características da sociedade brasileira e de quem a constrói cotidianamente, os indivíduos organizados em grupos sociais em um constante devir.

Por fim, por que a indisciplina de Darcy Ribeiro era progressista? Por que esse intelectual, um "livre atirador", por meio de suas ideias e ações, entre elas a BBB, revisitada e ampliada pela Fundar, procurava transformar a sociedade brasileira, em especial, por meio da política associada à educação? As palavras de Darcy, fortes pela natureza de quem as pronunciava, são categóricas quanto ao papel social da educação, em um discurso proferido durante uma reunião da Sociedade Brasileira para o Progresso da Ciência em 1977: "Sobre o óbvio". Após enumerar obviedades constituintes da realidade social brasileira, entre elas o papel histórico fundamental desempenhado pelas elites como forma de perpetuar as condições favoráveis à sua dominação, notadamente por meio da propriedade privada e da educação excludente, argumenta que: "Em consequência, a crise educacional do Brasil, da qual tanto se fala, não é uma crise, é um programa. Um programa em curso, cujos frutos, amanhã falarão por si mesmos" (RIBEIRO, 1979, p. 23).

Darcy Ribeiro compreendia claramente o papel das estruturas e das instituições no desenvolvimento da sociedade brasileira. De acordo com Bomeny (2001, p. 217), ele era “(...) um antropólogo militante e sociólogo de extração durkheimiana”, em que pese a influência do marxismo na sua formação, que compreendia que essas instituições eram protagonistas na constituição extremamente desigual dessa sociedade e que por isso, o projeto político e educacional alternativo deveria trilhar outro caminho: aquele que permitisse uma ampliação do acesso das classes populares à educação via instituições educacionais. Ao dar continuidade às ideias de Darcy Ribeiro, a Nova BBB editada pela Fundar integra, em alguma medida, esse caminho alternativo. Ao menos disponibiliza um instrumento às instituições educacionais para tal, e isso em tempos de conservadorismo deve ser celebrado e encarado como uma ação de cunho progressista.

Ademais, a investigação da sociedade brasileira orientada pela Nova BBB, preenchida por diferentes obras que enfatizam "os avanços e retrocessos de seu processo civilizatório", como já salientamos, provoca o seu leitor a pensar a sua própria relação com o país, o seu papel no funcionamento da educação, na cultura literária e na história. Um convite à transformação social e uma tarefa para todos aqueles que, em alguma medida, se consideram "indisciplinados" como Darcy Ribeiro. O roteiro de obras literárias pensado por ele ainda carrega enorme vitalidade e urgência na ampliação de suas bases sociais de circulação, e é uma iniciativa indispensável.

\section{Referências bibliográficas:}


BOMENY, Helena. Darcy Ribeiro: sociologia de um indisciplinado. Belo Horizonte: Ed. UFMG, 2001.

CASTRO, Eduardo, Viveiros de. O nativo relativo. Mana, Rio de Janeiro, v. 8, n. 1, p. 113-148, abr. 2002.

RIBEIRO, Darcy. UnB: invenção e descaminho. Rio de Janeiro: Avenir, 1978.

RIBEIRO, Darcy. Ensaios insólitos. Porto Alegre - RS: L\&PM Editores Ltda, 1979.

RIBEIRO, Darcy. O Povo Brasileiro: a formação e o sentido do Brasil. São Paulo: Companhia das Letras, 1995.

${ }^{1}$ As obras vinculadas podem ser "baixadas" no site da nova BBB: http://www.fundar.org.br/bbb/index .php/livros/

${ }^{2}$ Disponível em: http://www.fundar.org.br/bbb/index.php/a-colecao/ 